\title{
POR UM DESIGN AMBIENTAL ESPAÇO DE APLICAÇÃO: A REGIÃO DE SOROCABA
}

\author{
PAULO RENATO MESQUITA PELLEGRINO*
}

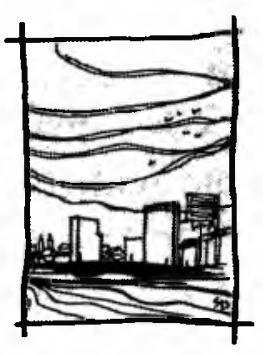

Parte da visão da cidade como um ECOSSISTEMA, ou seja: como um sistema aberto, singular, evolutivo e auto-regulável.

Pretende ser um esforço conceitual e metodológico no sentido de aplicação do conceito do ESPAÇO enquanto TOTALIDADE CONCRETA, com ênfase no processo de projetação (design) ambiental, como um instrumento de ampliação do conhecimento desta totalidade. Desta forma este trabalho se apresenta como uma oportunidade de discussão de aspectos da QUESTÃO AMBIENTAL, e da contribuição específica do Arquiteto, enquanto um intelectual ativista e designer ambiental; dado a sua capacidade de síntese entre as várias áreas do conhecimento, que sua formação generalista lhe permite enveredar, e a sua atribuição de criador de inputs capazes de realizarem mudanças evolutivas nos sistemas espaciais que lhe cabe intervir: tendo como objetivos:

1. A conservação dos recursos. vistos como a totalidade dos fatores suportes da vida;

2. Um processo de desenvolvimento verdadeiro e auto-sustentado;

3. A evolução do meio ambiente para estágios superiores de percepção sensorial, seja a nível do conforto como da estética.

Com este enfoque globalizante e sistêmico, não se distingue escalas e níveis estanques. Assim foi escolhido um espaço de aplicação numa escala que abrangesse diversos tipos de paisagens de forma que se possibilitasse a demonstração das múltiplas influências que os diversos tipos de ecossistemas exercem entre si, num processo dinâmico e acumulativo, e que forçosamente tem que estar considerados nas escalas menores de projetação, para que os desenhos daí resultantes, seja dos espaços livres ou edificados, consigam dar uma resposta positiva aos objetivos maiores: em que os ciclos e processos naturais mais o trabalho do Homem na natureza expressem um sistema ecologicamente integrado. 


\section{QUADRO DE REFERÊNCIA TEÓRICO}

\section{A POSIÇÃO FILOSÓFICA}

Como diz Kosik (1976), a realidade não se apresenta aos homens, à primeira vista. sob o aspecto de um objeto que cumpre intuir, analisar e compreender teoricamente, cujo pólo oposto e complementar seria justamente o abstrato sujeito cognoscente, que existe fora do mundo e apartado do mundo: mas sim como o campo em que se exercita a sua atividade prático-sensivel, sobre cujo fundamento surgirá a imediata intuição prática da realidade. No trato práticoutilitário com as coisas em que a realidade se revela como mundo dos meios, fins, instrumentos, exigências e esforços para satisfazer a estas - o indivíduo "em situação" cria suas próprias representações das coisas e elabora todo um sistema correlativo de noções que capta e fixa o aspecto fenomênico da realidade. E. segundo o mesmo autor, o conhecimento consiste na decomposição do todo, para poder reproduzir a estrutura da coisa. e, portanto, compreendê-la; lembrando ainda que não é possível compreender imediatamente a estrutura da coisa mediante uma mera contemplação ou reflexão, mas sim pela análise da atividade mediante a qual ela é compreendida, sendo que esta análise deve incluir também o problema da criação da atividade que estabelece o acesso à "coisa em si" atividades estas que são os vários aspectos ou modo da apropriação do mundo pelos homens. Considera, ainda, que o conhecimento deriva da atividade perceptiva, e que cada objeto percebido. observado ou elaborado pelo homem é parte de um todo, e precisamente este todo não percebido explicitamente é a luz que ilumina e revela o objeto singular: o que somado ao conhecimento das leis do movimento da coisa em si, explicando a realidade com base na própria realidade, mediante o desenvolvimento e a ilustração das suas fases, dos momentos do seu desenvolvimento, permite atingir a compreensão dos processos evolutivos da realidade. Chega-se então ao conceito da TOTALIDADE CONCRETA, em que a "realidade é entendida como concreticidade, como um todo que possui sua própria estrutura (e que, portanto, não é caótico), que se desenvolve (e, portanto, não é imutável nem dados uma vez por todas), que se vai criando (e que, portanto, não é todo perfeito e acabado no seu conjunto e não é imutável apenas em suas parte isoladas, na maneira de ordená-las), de semelhante concepção da realidade decorrem certas conclusões metodológicas que se convertem em orientação heurística e princípio epistemológico para estudo. descrição. compreensão, ilustração e avaliação de certas secções tematizadas da realidade, quer se trate da física ou da ciência literária. da biologia ou da política econômica, de problemas teóricos de matemática ou de questōes práticas relativas à organização da vida humana e da situação social" Ou como Santos (1985) também coloca, o espaço deve ser considerado como uma totali- 
dade, e considerá-lo assim exige que se encontre, através da análise, a possibilidade de dividi-lo em partes, permitindo ao seu término a reconstrução desse todo: e que a interdependência e a mediação da parte e do todo significam. Ao mesmo tempo que os fatos isolados são abstrações, elementos artificialmente separados do conjunto e que unicamente por sua participação no conjunto correspondente adquirem veracidade e concretude. Quanto à possibilidade de uma classificação, este autor defende que somente através do movimento do conjunto, isto é, do todo, ou do contexto, é que poderemos corretamente valorizar cada parte e analisá-la, para em seguida, reconhecer concretamente esse todo.

\section{SUBSÍDIO TEÓRICO}

Esta visão dialética. que possibilitou no desenvolvimento dos vários ramos do conhecimento o vislumbre de uma nova ciência unitária, encontra seu fundamento, segundo Kosik, em que todas as regiões da realidade objetiva são sistemas, isto é, conjunto de elementos que exercem entre si uma influência recíproca: o que faz citar Bertalanffly (1956) na constatação de que o problema essencial consiste em "relações organizadas que resultam da interação dinâmica, fazem com que o compontamento da parte seja diverso examinado isoladamente ou no interior de um todo"

Neste campo da teoria de sistemas, Berry (1972), a respeito dos Sistemas Espaciais. acrescenta que, ao mesmo tempo em que o mero fato da interdependência das partes foi um ponto crucial para o desenvolvimento anterior da análise do sistema social, as modernas análises de sistemas, vão mais longe para distinguir as espécies muito diferentes de inter-relações causais que sublimam a dinâmica ou estática dos diferentes tipos de sistemas; já que dentro de uma abordagem cibernética, as mútuas e reversíveis inter-relações de energia de um Sistema Espacial equilibrado, o fluxo negativo de retroalimentação de informação, tanto quanto a energia em sistema homeostásicos, e as interdependências de retroalimentação positiva adicionalmente encontrada em sistemas caracterizados pelo crescimento ou evolução, são fundamentais para um entendimento desses tipos de sistemas. Assim os Sistemas Espaciais se caracterizam por serem capazes de mudar ou elaborar suas estruturas como uma condição para manter sua viabilidade e continuidade como sistema: estrutura esta que é composta daquelas agregações de comportamento chamadas processos. que incorporam a idéia de crescimento, desenvolvimento. ritmo ou propriedade: processos que são irreversíveis. porque mudam seus próprios caracteres, numa mudança autogeradora.

Para Berry o modelo do Sistema Espacial é o ecossistema. um sistema funcional integrado. dos organismos vivos, inclusive o Homem e seus efetivos ambientes 
físicos, biológicos e culturais, frutos de processos naturais e culturais de entrosamento locacional e ambiental: movimento, locações, relações, ajustamentos, uso de recursos, etc.; mudando o sistema espacial de tal forma que, se a decisão tomada for biológica e culturalmente orientada e perceptualmente influenciada pelo ambiente, pode-se criar ambientes através de impactos nos processos naturais e culturais resultantes do comportamento espacial, dentro do sistema cibernético de retroalimentação. As ações que contribuem para processos espaciais podem ser de Manutenção (espaço-contigentes), Evolução (espaço formadores) ou Revolução (espaço transformadores). Se o primeiro tipo prevê sistemas complexos com poderosa auto-organização que tende a reprimir mudanças, é o último que insere em tais sistemas a capacidade de autotransformação em diferentes e novos estados, introduzindo a variedade que permite mudança construtiva. E, como Berry ainda diz: "ninguém discordará se dissermos que o estado corrente de qualquer sistema, descritível nos termos precedentes, é determinado pelos estados anteriores. Do mesmo modo o que dissemos anteriormente implica em que os estados futuros dos sistemas espaciais dependem do estado atual dos inputs externos do ambiente. e, porque a auto-regulação está presente de impulsos internos para conseguir futuros estados desejados (metas). $E$, se ações forem então tomadas para conseguir o estado futuro que se supõe desejável, o conceito do futuro é até certo ponto auto-realizável. Segue-se daí que na realidade dos empreendimentos humanos - e no planejamento de sistemas espaciais - meios e fins não podem jamais ser separados, mas são partes de processos entrelaçados"

Encontramos. também, em Klink (1974) um auxílio para esta nossa tentativa de análise, na sua proposta de Regionalização Natural a partir do conceito de "Ecologia da Paisagem" ou Geoecologia, que tem como propósito estabelecer as relações qualitativas e quantitativas entre os vários componentes do GEOCOMPLEXO (que compreende os vários componentes da crosta terrestre - a litosfera - solo + clima + cobertura), estudando a massa natural e balanços de energia de uma paisagem; com o entendimento da biosfera como a região que é caracterizada pela interpenetração dos vários componentes naturais e pelos efeitos especificamente orientados e de retroalimentação, a região que dá lugar à vida, que modela suas várias formas e que, por sua vez, é influenciada por ela, a mesma vida. que junto com os fatores ambientais forma na Terra unidades funcionais. os ECOSSISTEMAS que são espacialmente específicos e de escala variável. Propõe, então, este autor, a divisão da paisagem em UNIDADES NATURAIS, com o propósito de definir esta diferenciação espacial da biosfera. Lembra, ainda, que a abordagem geoecológica focaliza a investigação predominantemente nas relações funcionais e genéticas, na medida em que estas podem explicar o estado presente, e da oportunidade de aplicar a análise de sistemas no 
estudo da estrutura e das feições funcionais dos ecossistemas. Coloca que o uso de linhas limítrofes para representação de divisão entre as Unidades Naturais é o ponto mais questionável em qualquer classificação destas, já que o limite traçado entre duas unidades é apenas um instrumento intelectual usado para transmitir certa informação, e que apenas propósitos cartográficos justificam a conversão espacial dinâmica numa estrutura estática; acrescenta ainda que sobre as bases de uma tal divisão em Unidades Naturais, alguns mapas práticos poderiam ser desenvolvidos para determinar a capacidade ambiental em sofrer tensões e a capacidade de regeneração de certos fatores ambientais, assim como em responder questōes relativas ao uso do solo.

A investigação de um ecossistema com o propósito de se conseguir uma compartimentação em Unidades Naturais, deve começar pela identificação dos componentes que forma a sua ESTRUTURA, e que estão funcionalmente interrelacionados dentro do geocomplexo: Relevo, Substrato Geológico e Solos. Corpos d'água ou Balanço Hídrico, Clima nas escalas inferiores, e a Comunidade Biótica. Neste sentido, é particularmente importante determinar as interações e relaçōes especificamente orientadas entre os vários elementos, para que possamos processar então a sua classificação; tendo o GEOTOPO (fisiotopo + ecotopo) como a subdivisão fundamental que apresenta relativa uniformidade.

A importância prática da aplicação deste método de regionalização natural, como base para pesquisas ambientais, é defendida pelo próprio KLINK, ao conhecer que "o futuro conceito da geoecologia ... Não deve ser apenas restrito ao estudo das regiões naturais, as quais, de qualquer modo, são realmente um pouco mais de que entidades teóricas, mas também deveriam tomar numa base real todas as relações entre a vida e o ambiente material"

Neste contexto, outro autor, DELPOUX (1972), defende um avanço na análise e na compreensão dos fenômenos em todos os níveis onde a vida intervém, lançando-se mão da ação combinada de disciplinas e metodologias complementares, como a Geografia e a Ecologia, a partir de complexidade que é evidenciada pelo uso de termos como Ecossistema e Paisagem. Este mesmo autor comenta ainda que os estudos espaciais têm consistido em análises setoriais (Geomorfológicas, Urbanas, Climatológicas, Demográficas, Econômicas, não levando em consideração outros componentes dos conjuntos estudados. a não ser para situar os aspectos mais particularmente aprofundados, e que só atualmente se tem demonstrado que os problemas estão em evolução e que percepções globais dos fenômenos são possíveis. Exemplifica esta abrangência com a definição de BERTRAND (1968), de paisagem como a resultante de três componentes principais: o potencial abiótico, a exploração biótica e a utilização antrópica 
interferindo nos dois primeiros. Sobre esta definição DELPOUX coloca que todo os casos concretos de paisagens podem ser divididos em duas unidades elementares: o SUPORTE, que apresenta determinadas características (Forma, Cor. Textura) resultantes de influências geológicas, climáticas e antrópicas, e a sua COBERTURA, que materializa as influências climáticas, pedológicas e antrópicas (usos humanos presentes e passados, reflexos de atividades sócioeconômicas e culturais). Suporte e Cobertura estes, que sofrem variações no espaço e no tempo, e que somado à variação muito grande de combinações possíveis entre si, resulta na diversidade de tipos de paisagens existentes. Isto leva DELPOUX a definir paisagem como a entidade espacial correspondente à soma de um tipo geomorfológico e de uma cobertura no sentido mais amplo deste termo (da floresta à aglomeração urbana e à zona industrial passando pelas culturas e superfícies aquáticas). Ele introduz, então, o conceito de UNIDADE ELEMENTAR DE PAISAGEM ou seja, uma fração de crosta terrestre que pode ser qualificada de homogênea pelo suponte e pela cobertura simultaneamente, sendo que mesmo que exista heterogeneidade de estrutura (soma de seres vivos diferentes, tipos de culturas e de edificaçōes diferentes), esta se repete igual ou semelhante a si mesma: este conceito exclui qualquer critério preestabelecido de dimensão, e se completa com a idéia da Dinâmica Funcional, que anima estas unidades, que parte da definição de Ecossistema, e que resume todos os fatores de transferência (de matérias e energia), que são algumas vezes contínuas entre os diversos constituintes do espaço.

Todas as paisagens eram ecossistemas equilibrados até que o Homem passou a apoderar-se de certas técnicas e torná-las cada vez mais eficazes. redefinindo e aumentando o seu nicho ecológico. suscitando o aparecimento de estrutura localmente modificadas qualitativamente e desequilibradas energicamente, tornando possível falar de ecossistemas truncados: os quais de acordo com o seu balanço energético, podem ser caracterizados de paisagens exportadoras de energia (exemplo: culturas) ou paisagens importadoras de energia (exemplo: aglomeraçōes urbanas), que globalmente, assegurado pelos canais de alimentação e funcionamento do ecossistema, tendem a estabelecer um certo equilíbrio, mas com o risco permanente de que o princípio de entropia domine, estabelecendo inércias, gerando desequilibrios; o que vem a explicar a degradação sofrida por algumas paisagens modificadas/desequilibradas pelo homem.

Enfim, deve-se salientar ainda a importância que para nós assume neste processo de conhecimento, a percepção/experiência ambiental. com destaque aos aspectos da Forma/Figura (ou da configuração) da Paisagem: que está presente na definição dada por K. SAUER de Paisagem como "uma área é caracterizada por uma associação particular de formas. tanto físicas quanto humanas; acresce 
que as paisagens são unidades individuais de áreas e o que individualizaria as áreas seriam as associações particulares de formas ... é uma coisa corpórea que deve ser abordada pela caracterização das suas formas, que são reconhecíveis pela sua estrutura e compreendidas quanto à sua origem, crescimento e função"

\section{TENTATIVA DE MODELIZAÇĀO}

Com a visão das relações Natureza/Sociedade como um sistema aberto, singular, complexo, evolutivo e auto-regulável, como definido anteriormente; e que as relações da derivação da Natureza e exploração dos recursos pela sociedade devem garantir um processo evolutivo que assegure a otimização progressiva do Sistema: pode-se passar à elaboração de um Modelo Espacial/Temporal, com a finalidade de subsidiar o processo de Design.

As variáveis a serem utilizadas deverão possibilitar, então, uma análise integrada dos Sistemas Naturais incorporando as Derivações Antropogênicas. Esta análise de funcionamento do ambiente humano consistirá numa interpretação e qualificação dos vários fatores levantados, rebatidos em Unidades Ambientais (subdivisōes do espaço que apresentam uma homogeneidade em relação aos diversos fatores analisados, em uma extensão geográfica padrão), com a finalidade de criar-se um modelo para o diagnóstico e previsão dos impactos dos usos humanos da região. A valorização para uma classificação das UAs definirá:

\section{a) Valores quanto à produtividade}

a.1. Ecossistemas significativos para a conservação da diversidade genética de recursos vivos.

a.2. Sistema de proteção a variações microclimáticas prejudiciais.

a.3. Sistema de proteção a processos morfodinâmicos prejudiciais da paisagem.

a.4. Áreas propícias à estruturação e expansão das atividades urbanas habitacionais, de serviço e industriais.

a.5. Capacidade de uso das terras para fins agropecuários, florestais e extrativistas.

a.6. Fontes energéticas e de jazidas minerais.

b) Valores quanto ao aspecto crítico

b. 1. Processos de erosão e deslizamentos. 
b.2. Áreas de sedimentação e inundação.

b.3. Mananciais e qualidade das águas.

b.4. Conservação dos solos e processos de desertificação.

b.5. Poluição atmosférica e qualidade do ar.

c) Valores quanto a aspecios estéticos/perceptuais e culturais

c.1. Sítios únicos quanto a visuais e ao patrimônio ambiental.

c.2. Áreas com potencial recreacional.

\section{A APLICAÇĀO}

\section{O OBJETO DE ESTUDO}

Se considerarmos que a biosfera seja o sistema inicial, do qual os outros se originam, como subsistemas hierarquizados, com limites precisos, relações e interdependências; a delimitação da área sobre a qual se realiza a investigação poderia se resumir a uma decisão aleatória da escala, e conseqüente extensão geográfica, do subsistema no qual as variáveis essenciais ao nosso interesse se apresentam operacionalizáveis. Mas, quando considera-se também o meio ambiente humano como a interação entre os processos biofísicos e os culturais, com o ser humano como elemento dominante. capaz de impor modificações às compartimentações biofísicas existentes; surge uma atitude mais cautelosa com a subdivisão que melhor atenderia aos nossos objetivos.

Inicialmente nos ativemos à subdivisão fisiográfica da Bacia do Rio Sorocaba, em virtude de que os sinais mais visíveis de degradação ambiental, que se constatam na área, serem fenômenos crescentes de erosão, deslizamentos e inundações; que se rebatem no binômio SOLO/ÁGUA, os quais podem ser considerados, com a intermediação dos fatores climáticos, os elementos estruturadores da paisagem física. Deste modo tinha-se uma delimitação (pela bacia de drenagem superficial) que satisfazia os critérios necessários para um processo de projetação ambiental que fosse preferencialmente calcado no suporte físico-ecológico: ser uma unidade hidrológica, com evidentes variações quanto a aspectos fisiográficos e de domínios morfoloclimáticos, em uma extensão geográfica razoável de aproximadamente 4.000 km²; com situação central do estado de São Paulo, contínua à Região Metropolitana, tendo como pólo sócioeconômico, em seu centro geográfico, a conurbação de Sorocaba/Votorantim: apresentar um pa- 
trimônio cultural e natural exigente de uma ação de valorização e conservação, somado à previsão de uma expansão crescente nos usos urbanos nas suas atividades econômicas, em especial a industrialização.

O desenvolvimento da reflexão sobre a problemática veio a introduzir modificações na tentativa de aplicação do conceito do espaço enquanto totalidade. $O$ recorte do objeto de estudo passa a não poder se restringir apenas à base fisiográfica. mas a ter uma delimitação variável de acordo com as relações definidas pelas análises temáticas como necessárias: o subespaço "Core" definido pela sobreposição das diversas delimitações nos dá o objeto a ser projetado: $O$ aglomerado urbano de Sorocaba/Votorantim e o seu enquadramento ambiental.

As variáveis e os índices operativos definidos como relevantes e que se constituem no nosso universo de coleta de dados, foram organizados como segue:

\section{a) Fatores Físicos/Geometria Espacial/Suporte Abiótico}

a.1. Compartimentação geomorfológica:

a.1.1. Geologia.

a.1.2. Solos.

a.1.3. Rede de drenagem superficial.

a.1.3.1. Ciclos, cheias e vazantes.

a.1.3.2. Qualidade das águas.

a.1.3.3. Pontos críticos de erosão e sedimentação.

a.1.4. Águas subterrâneas.

a.1.4.1. Permeabilidade dos terrenos.

a.1.4.2. Aquiíferos, mananciais e bacias de adução.

a.1.5. Topografia.

a.1.5.1. Hipsometria.

a.1.5.2. Plateaux, divisores, talvegues e vertentes.

a.1.5.3. Declividades.

a.1.5.4. Exposição de vertentes.

a.2. Aspectos Climatológicos:

a.2.1. Precipitações, máxima intensidade, sazonalidade, totais anuais, número de dias de ocorrência.

a.2.2. Temperatura, máxima, mínima, médias, isoietas.

a.2.3. Insolação, dias/ano e horas/dia.

a.2.4. Ventos, velocidade e direção.

a.2.5. Condições sinóticas. 


\section{b) Fatores Biológicos/Cobertura original/Suporte biótico}

b.1. Vegetação:

b.1.1. Distribuição e tipologia.

b.1.2. Ecologia.

b.2. Fauna:

b.2.1. Habitats terrestres e aquáticos.

b.2.2. Ecologia.

c) Fatores Culturais/Espaços produtivos/Derivação Antropogênica

c.1. Aspectos Perceptuais e Patrimônio Cultural:

c.1.1. Visuais e sítios únicos, aspectos estéticos da paisagem.

c.1.2. Áreas de interesse geológico, antropológico, arqueológico e histórico.

c.2. Aspectos sócioeconômicos.

c.2.1. Evolução e organização das atividades humanas.

c.2.2. Regionalização, hierarquização e polarização.

c.2.3. Rede urbana, fluxos, comunicações e acessibilidade.

c.2.4. Uso do solo, atividades primárias, secundárias e terciárias.

c.2.5. População, características, distribuição e mobilidade.

c.2.6. Aspectos institucionais, legislações, restrições e competências.

c.2.7. Planos, políticas e diretrizes que afetem a área.

\section{BIBLIOGRAFIA}

\section{A POSIÇĀO FILOSÓFICA}

DORST, Jean. A força do ser vivo. São Paulo: Melhoramentos/EDUSP, 1981, 175p.

GONÇALVES, Carlos W. P. Paixāo da terra: ensaios críticos de ecologia e geografia. Rocco, 1984, 160p.

KOSIK, Karel. A dialética do concreto. Rio de Janeiro: Paz e Terra, 1976.

MONTEIRO, Carlos Augusto de Figueiredo. Teoria e clima urbano. São Paulo: IGEOGUSP, 1976, 181 p. Série Teses e Monografia, nº 25.

MORONI, Antonio. Ideas para una proyectación del ambiente humano, in: fichas CEPA: Centro de Estudos y Proyectacion de Ambiente, $1^{\underline{a}}$ ed. Buenos Aires: Editorial Libreria Tecnica - CP 767, 1974, 42p. 
SANTOS, Milton. Espaço e método. São Paulo: Nobel, 1985, 88p.

WILKINSON, Richard. Pobreza e progresso: um modelo ecológico de desenvolvimento econômico. Rio de Janeiro: Zahar, 238p.

\section{SUBSÍDIO TEÓRICO}

BERRY, Brian J. L. Mudanças deliberadas nos sistemas espaciais: Metas estratégias $e$ sua araliaçāo. São Paulo: Instituto de Geografia da USP, 1975, 25p.

CHURCHMAN, C. West. Introduçāo à teoria dos sistemas.

DELPOUX, Marcel. Ecossistema e paisagem. São Paulo: Instituto de Geografia da USP, 1974, 23p.

FOIN JR., Theodorore C. Ecological sistems and the environment. Houghton Mifflin, $591 \mathrm{p}$.

HACKETT, Brian. Landscape planning: an introduction to theory and practice. New Castle Upon Tyne: Oriel, 1971, 124p.

HALPRIN, Lawrence. RSVP cycles: creative processes in the human environment. New York: Brasiliense, 1969.

KLINK, Hans J. Geoecologia e regionalizaçāo natural: bases para pesquisa ambiental. São Paulo: FFLCHUSP, Departamento de Geografia, 1981, 24p.

Mc HARG, Ian. Design with nature. New York: The Natural History, Press, 1969, 197p.

MONTEIRO, Carlos Augusto de Figueiredo. Derivações antropogênicas dos Geossistemas Terrestres no Brasil e alterações climáticas: Perspectivas urbanas e agrárias ao problema da elaboração de modelos de avaliação. ACIESP, $n^{\circ} 15$, São Paulo, 1978.

SOCTHAVA, V. B. Por uma teoria de classificaçāo de geossistemas de vida terrestre. São Paulo: Instituto de Geografia-USP, 24p.

TRICART. Paysage e ecologia. Strasbourg.

\section{TENTATIVA DE MODELIZAÇÃO}

ANÁLISE Biofísica relevo. Instituto Universitário de Évora. Curso de Planejamento Biofísico, cadeira de arquitetura paisagística I, 1977, jan. xerox. 
ANDERSON, James R. Sistema de classificaçāo do uso da terra e do revestimento do solo para utilizaçāo com dados de sensores remotos. Trad. Harold Strang, Rio de Janeiro: IBGE/SUPREN, 1979, (Série Paulo de Assis Ribeiro).

CATENESE, Anthony J. Scientific methods of urban analysis. Urbana University of Illinois Press, 1972, 336p.

CPE Centro de Planejamento e Estudo. A compatibilização dos usos do solo e a qualidade ambiental na regiāo central da Bahia. Salvador: CPE, 1981, 87p. (Série Recursos Naturais)

DANTAS, Jorge R. Modelos urbanos: um enfoque cientifico no planejamento urbano. São Paulo: FAUUSP, 1984, 196p.

DOUGENIK, James A., SHEEHAN, David E. SYMAP User's reference manual. 5 ed., Laboratory for Computer Graphics and Spatial Analysys. Harvard University, september, 1975.

ECHENIQUE, Marcial. Models: a discussion in urban space and structures. Cambridge University Press, 1972. p. 164-175.

HARRIS, Britton. Modelos de desarollo urbano. Barcelona: Oikos, 1975, 144p.

LUCAS, Manoel Galvão. Arquitetura paisagística no planejamento físico-territorial. Porto Alegre: GG Edições Técnicas. $101 \mathrm{p}$.

MARSH, Willian et alli. Enviromental analysis: for land $r s e$ and site planning. New York: Mac Graw Hill, 1978, 292p.

NOVAES, Antonio G. Modelos em planejamento urbano, regional e de transportes. São Paulo: Editora Edgard Bluches Lida. 1982, 289 p.

PESCI, Rubens O. Impacto sobre el ambiente. in fichas CEPA: Centro de Estudios y Proyectacion del Ambiente, Buenos Aires: Espacio Editora, 1977, 69 p. (Série Planeamiento y Sociedad - ficha nº 2).

Texto originalmente publicado no Paisagem e Ambiente - Ensaios II.

$\left.{ }^{*}\right)$ Arquiteto PUCCAMP. mestre e doutorando FAUUSP. professor e pesquisador do Grupo de Disciplinas Paisagem e Ambiente do Departamento de Projeto - FAUUSP. 